\title{
Effects of antenatal corticosteroids administration on fetoplacental circulation in preterm pregnancies with intrauterine growth restriction and its correlation with perinatal outcome
}

\author{
Neelima Choudhary ${ }^{1 *}$, Ashima Kesri ${ }^{1}$, Shilpi Nain ${ }^{2}$, Vikas Chaudhary ${ }^{3}$, S. S. Trivedi ${ }^{4}$
}

\author{
${ }^{1}$ Department of Obstetrics and Gynecology, ESIC Medical College and Hospital, Faridabad, Haryana, India \\ ${ }^{2}$ Department of Obstetrics and Gynecology, Lady Hardinge Medical College, New Delhi, India \\ ${ }^{3}$ Department of Radiology, Lady Hardinge Medical College, New Delhi, India \\ ${ }^{4}$ Department of Obstetrics and Gynecology, SGT Medical College, Gurugram, Haryana, India
}

Received: 13 April 2020

Accepted: 05 May 2020

\section{* Correspondence:}

Dr. Neelima Choudhary,

E-mail: choudhary.neelima13@gmail.com

Copyright: () the author(s), publisher and licensee Medip Academy. This is an open-access article distributed under the terms of the Creative Commons Attribution Non-Commercial License, which permits unrestricted non-commercial use, distribution, and reproduction in any medium, provided the original work is properly cited.

\begin{abstract}
Background: Antenatal corticosteroid administration in preterm pregnancies is recommended to promote fetal lung maturation. Studies have reported temporary reduction in fetal heart rate, breathing and movements following maternal corticosteroid administration. Authors studied effect of maternal corticosteroid administration on fetoplacental circulation in preterm pregnancies with IUGR and its correlation with perinatal outcome.

Methods: Observational study included 77 preterm singleton pregnant women with IUGR. Color doppler day 0 (before betamethasone) of umbilical artery of 77 cases done. All received two doses of $12 \mathrm{mg}$ of betamethasone intramuscularly 24 hours apart. Umbilical artery doppler on day 2 ( 24 to 48 hours of $1^{\text {st }}$ dose of betamethasone) and day 4 (72 to 96 hours of 1 st dose of betamethasone) done. Pulsatility index (PI) of umbilical artery on doppler and Neonatal details of all women noted.

Results: On day 2 doppler, 56 (73\%) women (Group A) showed decrease in umbilical artery PI while 21 (27\%) women (Group B) did not show decrease in umbilical artery PI. Mean umbilical artery PI of 77 cases on day 0 and day 2 were $1.73 \pm 0.73$ and $1.54 \pm 0.76$ respectively $(p<0.001)$. Mean Umbilical artery PI values of undelivered 60 cases on day 0 , day 2 and day 4 were $1.55 \pm 0.61,1.33 \pm 0.55$ and $1.47 \pm 0.63$ respectively ( $<<0.001$ ). Group B neonates had poorer Apgar scores, higher neonatal complication, longer hospital stay, lesser umbilical pH at birth and higher perinatal mortality rate than Group A neonates.

Conclusions: Significant reduction in mean umbilical artery PI observed on day 2 following betamethasone administration $(\mathrm{p}<0.001)$, which was maintained till $4^{\text {th }}$ day after $1^{\text {st }}$ dose of betamethasone $(\mathrm{p}<0.05)$. Women who showed improvement in umbilical artery pulsatility index following betamethasone administration had a better perinatal outcome as compared to women who did not.
\end{abstract}

Keywords: Antenatal corticosteroid, Betamethasone, Intrauterine growth restriction, Perinatal outcome, Umbilical artery pulsatility index

\section{INTRODUCTION}

Pregnancy complicated with intrauterine growth restriction roughly constitute $3-10 \%$ of all pregnancies. ${ }^{1}$ The incidence is higher in developing countries including India.
Pregnancy with intrauterine growth restriction (IUGR) before 34 weeks are at a higher risk of preterm delivery. Antenatal administration of betamethasone in these preterm pregnancies is recommended to promote fetal lung maturation, reduces the incidence and severity of respiratory distress syndrome and complications like 
necrotizing enterocolitis, intra ventricular hemorrhage and neonatal death. ${ }^{2-6}$ Doppler ultrasonography examination is an important tool of fetal surveillance in such cases.

Few studies have reported a temporary reduction in fetal heart rate, fetal breathing movements and fetal movement following maternal administration of betamethasone. ${ }^{7,8}$ These transient effects really affect the fetus or not, still remains controversial.

Hence, authors conducted this study to evaluate the effect of maternal Betamethasone administration on fetoplacental circulation by evaluating Doppler indices in preterm pregnancies with intrauterine growth restriction and the effect of these fetoplacental circulation changes on perinatal outcome, if any.

\section{Aims and objectives}

- To study the umbilical artery doppler changes on Doppler ultrasonography following maternal betamethasone administration in preterm pregnancies with fetal growth restriction.

- To study the effect of these fetoplacental circulation changes on perinatal outcome following betamethasone administration in preterm pregnancies with fetal growth restriction.

\section{METHODS}

This study was carried out in the department of obstetrics and gynecology in collaboration with the department of Radiology, at Lady Hardinge Medical College and Smt. Sucheta Kriplani Hospital, New Delhi.

This was observational study. A total of 77 preterm pregnant women with intrauterine growth restriction admitted in the antenatal ward of SSK Hospital were included in the study.

\section{Inclusion criteria}

- Women having singleton pregnancies with gestation age from 26 to 34 weeks complicated with intrauterine growth restriction on clinical examination and ultrasound.

\section{Exclusion criteria}

- Women with multiple pregnancies, singleton pregnancies with fetal anomalies and women where two doses of corticosteroids could not be completed were excluded from the study.

This study was approved by Ethics Committee of Lady Hardinge Medical College (University of Delhi). A written informed consent for participation was obtained from each woman included in this study at the time of enrolment.
A detailed history, examination and routine investigations of every woman enrolled in this study were being done.

Cases with clinically suspected IUGR were subjected to obstetrical ultrasonography for fetal biometric parameters, estimation of gestational age, Amniotic Fluid index (AFI), estimated fetal weight (EFW), for detection of any congenital anomaly, placental localization and placental maturity.

After confirmation of IUGR, color Doppler blood flow study (day 0 doppler) of umbilical artery of all the cases was done and noted. The Doppler examinations were done transabdominally with the fetus in a quite state, without fetal movements and without fetal breathing movements and during maternal voluntary apnea.

The Doppler examination was performed using ALTHD1 5000 (SIEMENS) with a 3-5 MHz transducer. Doppler waveforms from umbilical artery were recorded in the free-floating mid portion of umbilical cord. Doppler indices as umbilical artery PI value were noted.

Pulsatility index $=$ systolic peak velocity - end diastolic peak velocity / time averaged maximum velocity;

Preterm pregnant women with IUGR were treated with two doses of $12 \mathrm{mg}$ of betamethasone intramuscularly 24 hours apart.

Repeat Doppler examinations (day 2 Doppler) of the umbilical artery were performed between 24 to 48 hours (day 2) of 1st dose of betamethasone of all 77 women and findings were recorded.

A third Doppler examination (day 4 Doppler) of umbilical artery (UA) was done between 72 to 96 hours of $1^{\text {st }}$ dose of betamethasone administration in 60 women who did not deliver within 72 hours of $1^{\text {st }}$ dose of betamethasone administration and noted.

Decision about time and mode of delivery was taken according to the risk assessment of the fetus and mother on an individual basis as per management protocol for pregnancies with IUGR.

All neonatal details as birth weight, Apgar score, resuscitative measures needed at birth, umbilical artery $\mathrm{pH}$ at birth, base excess, admission to neonatal intensive care (NICU), any neonatal complication, total hospital stay of neonate and neonatal mortality were noted.

Pulsatility Index values of umbilical artery of all 77 women obtained before (day 0) and after (day 2) betamethasone administration were compared and analysed.

Pulsatility index of umbilical artery on day 4 (between 72-96 hours) of $1^{\text {st }}$ dose of betamethasone of 60 women who did not deliver within 72 hours of betamethasone 
administration, were compared with their day 0 and day 2 Doppler values respectively and analysed statistically.

Perinatal outcome of women who had shown decrease in umbilical artery PI (Group A) following betamethasone administration were compared with those women's perinatal outcome who had not shown decrease in umbilical artery pulsatility index (Group B) following betamethasone administration.

\section{Statistical analysis}

Tabulated data was analyzed statistically by using appropriate statistical tests which included paired t-test, Pearson chi-square test and ANOVA.

\section{RESULTS}

A total 77 women included in the study were between the age of 19-34 years with mean age of cases was 25.10 \pm 3.2 years (Figure 1). $75 \%$ of cases included in this study were between gestational age of 30-34 weeks (Figure 2). 27 cases $(40 \%)$ were primigravida, 16 cases $(24 \%)$ were $2^{\text {nd }}$ gravida, 16 cases $(24 \%)$ were third gravida (Figure 3 ). In this study group, $60 \%$ of multigravida women had a history of abortion, previous IUGR, intrauterine death (IUD)/still birth.

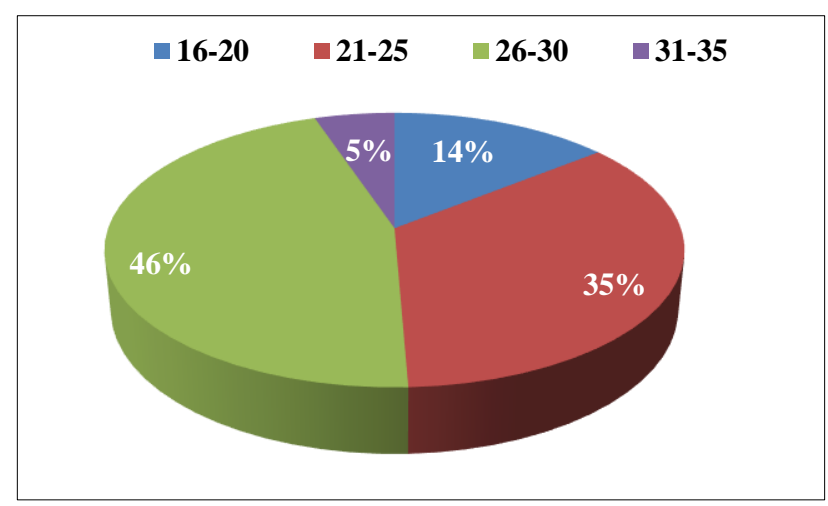

Figure 1: Distribution of cases according to age (years).



Figure 2: Distribution of cases according to period of gestation (POG).

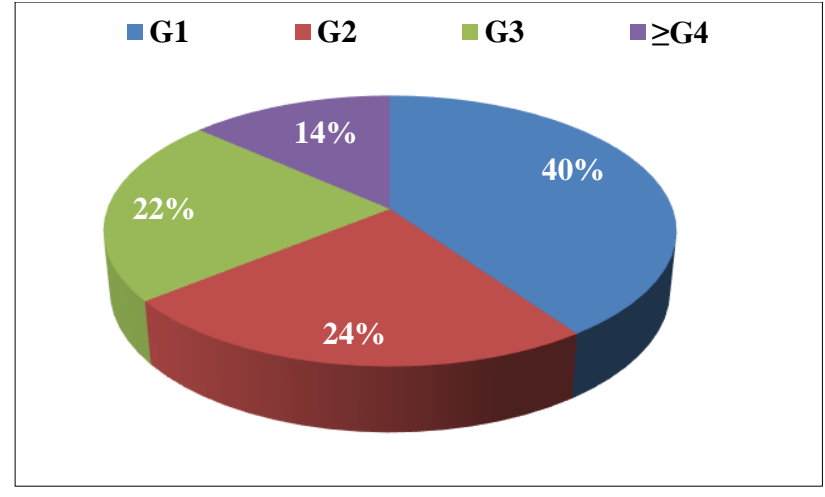

Figure 3: Distribution of cases according to parity.

A total $34(44.2 \%)$ women out of total 77 had pregnancy induced hypertension. Out of these 34 women with PIH, $20(51 \%)$ women had mild PIH and 14 (41\%) women had severe PIH. Anemia was present in 26 (33.8\%) women out of 77 women. No other medical illness was observed in this study group. Mean SFH lag (difference between period of gestation (weeks) and symphysio fundal height) was $4.84 \pm 1.01 \mathrm{cms}$. (range 3.2-8.1 cms).

Table 1: Obstetric ultrasonographic details of women (total 77 cases).

\begin{tabular}{|lll|}
\hline Parameter & Mean \pm SD & Range \\
\hline $\begin{array}{l}\text { Gestational age on admission } \\
\text { by LMP* (weeks) }\end{array}$ & $32.1 \pm 1.52$ & $27.4-34$ \\
\hline $\begin{array}{l}\text { Gestational age by biparietal } \\
\text { diameter (weeks) }\end{array}$ & $31.3 \pm 2.0$ & $26.9-34.1$ \\
\hline $\begin{array}{l}\text { Gestational age by femoral } \\
\text { length (weeks) }\end{array}$ & $30.6 \pm 1.7$ & $28-33$ \\
\hline $\begin{array}{l}\text { Gestational age by } \\
\text { abdominal circumference } \\
\text { (weeks) }\end{array}$ & $28.7 \pm 0.93$ & $27-30$ \\
\hline $\begin{array}{l}\text { Estimated fetal weight } \\
\text { (grams) }\end{array}$ & $1207 \pm 216$ & $430-1769$ \\
\hline Amniotic fluid Index (cms) & $6.14 \pm 3.16$ & $0-11$ \\
\hline
\end{tabular}

*LMP: last menstrual period.

Ultrasonographic details of the study population have been tabulated in Table 1 .

Authors noted the following two important observations and analysed the same.

\section{Effect of betamethasone administration on umbilical artery pulsatility index}

Doppler examination of all cases on day 0 (before betamethasone administration) showed that out of 77 women of this study, $26(33.7 \%)$ women had umbilical artery pulsatility index (PI) $<1.45$ and $51(66.3 \%)$ women had umbilical artery pulsatility index $(\mathrm{PI}) \geq 1.45$.

Out of 77 women, 56 (73\%) women showed a decrease in umbilical artery pulsatility index on day 2 (24-48 hours) 
following betamethasone administration (Group A). Rest 21 (Group B) women (27\%) did not display any decrease in umbilical artery pulsatility index following betamethasone Table 2 .

Mean umbilical artery pulsatility index (PI) value of 77 cases on day 0 (before betamethasone) and day 2 (between 24-48 hours of $1^{\text {st }}$ dose of betamethasone) were $1.73 \pm 0.73$ (range 0.67-3.7) and 1.54 \pm 0.76 (range 0.533.78) respectively. Decrease found in umbilical artery PI value following betamethasone administration on day 2 was statistically significant $(\mathrm{p}<0.001)$ Table 3 .
Table 2: Effect of betamethasone administration on umbilical artery pulsatility index (PI).

\begin{tabular}{|c|c|c|c|}
\hline $\begin{array}{l}\text { Chang } \\
\text { followi } \\
\text { total ce }\end{array}$ & $\begin{array}{l}\text { mbilical ar } \\
\text { tamethasor } \\
=77\end{array}$ & $\begin{array}{l}\text { pulsatility } \\
\text { etween day }\end{array}$ & $\begin{array}{l}\text { ex } \\
\text { to day 2) }\end{array}$ \\
\hline $\begin{array}{l}\text { Decrea } \\
\text { (GrouI }\end{array}$ & PI & $\begin{array}{l}\text { No decrease } \\
\text { (Group B) }\end{array}$ & n PI \\
\hline $\begin{array}{l}\text { No. of } \\
\text { cases }\end{array}$ & Percentage & No. of cases & Percentage \\
\hline 56 & $73 \%$ & 21 & $27 \%$ \\
\hline
\end{tabular}

Table 3: Effect of betamethasone administration on pulsatility index of umbilical artery.

\begin{tabular}{|llll|}
\hline Doppler indices & Day 0 (before) & Day 2 (after) & p value $0 / 2^{\alpha}$ \\
\hline Umbilical artery PI mean \pm SD (range) & $1.73 \pm 0.73(0.67-3.7)$ & $1.54 \pm 0.76(0.53-3.78)$ & $<0.001(\mathrm{~S})$ \\
\hline $\begin{array}{l}\text { Day 0- before betamethasone administration and day 2- between 24-48 hours after first dose of betamethasone administration. }{ }^{\alpha} 0 / 2- \\
\text { p Value of difference between day } 0 \text { and day 2 mean PI values. S-significant. }\end{array}$
\end{tabular}

Table 4: Comparison of umbilical artery pulsatility index before (day 0 ) and after (day 2 and day 4) betamethasone administration in undelivered 60 cases.

\begin{tabular}{|c|c|c|c|c|c|c|}
\hline \multirow{2}{*}{ Doppler index } & \multirow{2}{*}{ Day 0} & \multirow{2}{*}{ Day 2} & \multirow{2}{*}{ Day 4} & \multicolumn{3}{|l|}{ p value } \\
\hline & & & & $0 / 2^{\alpha}$ & $2 / 4^{\alpha}$ & $0 / 4^{\alpha}$ \\
\hline Umb. A PI mean \pm SD & $1.55 \pm 0.61$ & $1.33 \pm 0.55$ & $1.47 \pm 0.62$ & $<0.001(\mathrm{~S})$ & $<0.001(\mathrm{~S})$ & $<0.05(\mathrm{~S})$ \\
\hline
\end{tabular}

Umb. A: umbilical artery, ${ }^{\alpha} \mathrm{p}$ value $0 / 2$ : between day 0 and day 2 value, $2 / 4$ : between day 2 , day 4 value and $0 / 4$ between day 0 and day 4 value, S: significant, NS: not significant. Day 0: Before betamethasone, day 2: 24-48 hours after first dose of betamethasone administration and day 4: 72-96 hours of $1^{\text {st }}$ of betamethasone.

Table 5: Basic characteristics of group A (56 cases) and group B women (21 cases).

\begin{tabular}{|llll|}
\hline Clinical features & $\begin{array}{l}\text { Women who showed decrease } \\
\text { in Umb. A. PI on day 2 } \\
\text { (Group A) } \mathbf{n = 5 6}(\mathbf{7 2 . 7} \%)\end{array}$ & $\begin{array}{l}\text { Women who did not show any } \\
\text { decrease in Umb. A PI on day 2 } \\
\text { (Group B) n=21 (27.2\%) }\end{array}$ & p value \\
\hline $\begin{array}{l}\text { Maternal age mean } \pm \text { SD } \\
\text { (years) }\end{array}$ & $24.66 \pm 1.2$ & $26.88 \pm 1.32$ & $>0.05$ (NS) \\
\hline $\begin{array}{l}\text { Gestational age in weeks at } \\
\text { admission mean } \pm \text { SD }\end{array}$ & $32.1 \pm 1.5$ & $31.8 \pm 1.4$ & $>0.05$ (NS) \\
\hline $\begin{array}{l}\text { Gestational age in weeks at } \\
\text { delivery mean } \pm \text { SD (range) }\end{array}$ & $34.3 \pm 1.88(30-37.2)$ & $33.9 \pm 1.2(29-37)$ & $>0.05$ (NS) \\
\hline $\begin{array}{l}\text { Interval in days between } 1^{\text {st }} \\
\text { dose of betamethasone and } \\
\text { delivery. mean (range) }\end{array}$ & $15.5(2-36)$ & $13.4(2-38)$ & $>0.05$ (NS) \\
\hline $\begin{array}{l}\text { Hypertension number of } \\
\text { cases }(\%)\end{array}$ & $22(39.3 \%)$ & $12(57.1 \%)$ & $>0.05$ (NS) \\
\hline $\begin{array}{l}\text { EFWT* } * \text { in grams } \\
\text { mean } \pm \text { SD (range) }\end{array}$ & $1231 \pm 273$ & $1143 \pm 342$ & $>0.05$ (NS) \\
\hline
\end{tabular}

Day 2 indicates between 24-48 hours after $1^{\text {st }}$ dose of betamethasone administration, NS-not significant.

Out of total 77 cases, 17 women delivered within 72 hours of $1^{\text {st }}$ dose of betamethasone administration. Day 4 doppler was done of the remaining 60 undelivered women only. Mean umbilical artery PI values of undelivered 60 cases on day 0 , day 2 and day 4 were
$1.55 \pm 0.61,1.33 \pm 0.55$ and $1.47 \pm 0.63$ respectively. The difference in mean umbilical artery PI values between day 0 and day 2 were statistically significant $(\mathrm{p}<0.001)$. A significant increase in mean umbilical artery pulsatility index (PI) from day 2 to day 4 was observed in these 60 
women $(p<0.001)$ Table 4. Authors observed that in spite of this rise in mean umbilical artery PI value from day 2 to day 4, umbilical artery mean PI value of day 4 still remained lower than umbilical artery mean PI on day 0 (before betamethasone).

The difference in mean umbilical artery PI between day 0 and day 4 were still statistically significant $(\mathrm{p}<0.05)$.

On comparison of basic characteristics of women of Group A and Group B, no statistically significant difference was notes in terms of maternal age, mean gestational age at admission, mean gestational age at delivery, interval between first dose of betamethasone to delivery, mean estimated fetal weight and associated complication like PIH Table 5.

\section{Comparison of perinatal outcome}

Significantly more IUDs (28.6\% versus $5.3 \%)$ occurred among women who did not show any reduction in umbilical artery PI (Group B) compared to women who showed reduction of umbilical artery PI on day 2 following betamethasone (Group A) $(\mathrm{p}<0.05)$. Mean birth weight was higher (1489 grams versus 1319 gms) in women who had reduction in umbilical artery PI but was statistically insignificant ( $\mathrm{p}$ value $>0.05$ ).

Mean birth weight of fetuses who had intrauterine death (IUD) was ranging from 680-800 grams.

All these fetuses, who had IUD were severely growth restricted with severely compromised fetoplacental circulation Table 6.

Neonates of women who had not shown any reduction in umbilical artery pulsatility index (Group B) required more of assisted ventilation and resuscitation and had poorer Apgar scores than neonates of women who showed reduction in umbilical artery pulsatility index following betamethasone administration ( $\mathrm{p}$ value $<0.05$ ) Table 7 and Table 8.

Table 6: Comparison of perinatal outcome between women of group A and group B.

\begin{tabular}{|llllll|}
\hline \multirow{2}{*}{ Perinatal outcome (total cases 77) } & Group A (56) & \multicolumn{3}{c|}{ Group B (21) } \\
\cline { 2 - 5 } & No. of cases & Percentage & No. of cases & Percentage & p value \\
\hline Live & 53 & $94.7 \%$ & 15 & $71.42 \%$ & $<0.05(\mathrm{~S})$ \\
\hline IUD* & 3 & $5.3 \%$ & 6 & $28.6 \%$ & \\
\hline Birth weight in grams mean \pm SD (range) & $1489 \pm 396(680-2200)$ & $1319 \pm 469(760-2100)$ & $>0.05(\mathrm{NS})$ \\
\hline
\end{tabular}

*IUD-intrauterine death.

Table 7: Need for resuscitative measures between neonates of group A and group B.

\begin{tabular}{|c|c|c|c|c|c|}
\hline \multirow[t]{2}{*}{$\begin{array}{l}\text { Resuscitation } \\
\text { method }\end{array}$} & \multicolumn{2}{|c|}{$\begin{array}{l}\text { Women with reduction in } \\
\text { umb. artery PI on day } 2 \\
\text { Group A }(n=53)\end{array}$} & \multicolumn{2}{|c|}{$\begin{array}{l}\text { Women without reduction in } \\
\text { umb. artery PI on day } 2 \\
\text { Group B }(n=15)\end{array}$} & \multirow[t]{2}{*}{ p value } \\
\hline & No. of cases & Percentage & No. of cases & Percentage & \\
\hline Routine & 32 & $60.3 \%$ & 3 & $20 \%$ & \multirow{3}{*}{$<0.05(\mathrm{~S})$} \\
\hline Bag and mask & 14 & $26.4 \%$ & 7 & $46.7 \%$ & \\
\hline IPPV and endotracheal intubation & 7 & $13.2 \%$ & 6 & $40 \%$ & \\
\hline
\end{tabular}

Table 8: Apgar Score of neonates in group A and group B women.

\begin{tabular}{|c|c|c|c|c|c|c|}
\hline \multirow[t]{2}{*}{ Time } & \multirow[t]{2}{*}{ Apgar Score } & \multicolumn{2}{|c|}{$\begin{array}{l}\text { Women with reduction in } \\
\text { umb. artery PI on day } 2 \\
\text { Group A ( } 53 / 77 \text { cases) }\end{array}$} & \multicolumn{2}{|c|}{$\begin{array}{l}\text { Women without reduction in } \\
\text { umb. artery PI on day } 2 \\
\text { Group B ( } 15 / 77 \text { cases) }\end{array}$} & \multirow[t]{2}{*}{ p value } \\
\hline & & No. of cases & Percentage & No. of cases & Percentage & \\
\hline \multirow{3}{*}{$\begin{array}{l}\text { At } 1 \\
\min \end{array}$} & $<5$ & 7 & $13.2 \%$ & 4 & $26.7 \%$ & \multirow{3}{*}{$>0.05(\mathrm{NS})$} \\
\hline & $5-7$ & 23 & $43.4 \%$ & 6 & $40 \%$ & \\
\hline & $>7$ & 23 & $43.4 \%$ & 5 & $33.3 \%$ & \\
\hline \multirow{3}{*}{$\begin{array}{l}\text { At } 5 \\
\min \end{array}$} & $<5$ & 0 & $0 \%$ & 0 & $0 \%$ & \multirow{3}{*}{$>0.05(\mathrm{NS})$} \\
\hline & $5-7$ & 15 & $28.3 \%$ & 6 & $40 \%$ & \\
\hline & $>7$ & 38 & $71.7 \%$ & 9 & $60 \%$ & \\
\hline \multirow{3}{*}{$\begin{array}{l}\text { At } 10 \\
\min \end{array}$} & $<5$ & 0 & $0 \%$ & 0 & $0 \%$ & \multirow{3}{*}{$>0.05(\mathrm{NS})$} \\
\hline & $5-7$ & 6 & $11.3 \%$ & 4 & $26.4 \%$ & \\
\hline & $>7$ & 47 & $88.7 \%$ & 11 & $73.3 \%$ & \\
\hline
\end{tabular}


Mean umbilical cord PH was lower and base excess value was higher in neonates of women who did not show reduction in umbilical artery PI (Group B) as compared to neonates of women who showed (Group A) ( $>0.05)$ Table 9. Authors observed that although the difference was not statistically significant, but neonates of Group B had higher incidence of respiratory distress syndrome, hypoglycemia, hypothermia, hyperbilirubinemia, hypocalcemia, intra ventricular hemorrhage, sepsis and broncho-pulmonary dysplasia (BPD) in neonatal period as compared to neonates of women of Group A Table 9. Neonates of Group A needed lesser (47\% versus 66.6\%) admissions to neonatal intensive care unit (NICU), shorter hospital stays of neonates as compared to Group B women's neonates. Neonatal mortality was higher $(13.3 \%)$ in Group B as compared to Group A (5.6\%. Perinatal mortality was significantly higher $(38.1 \%)$ in Group B as compared to Group A $(10.7 \%)(\mathrm{p}<0.05)$ (Table 9).

Table 9: Neonatal complications in group $\mathbf{A}$ and group $\mathbf{B}$.

\begin{tabular}{|c|c|c|c|}
\hline $\begin{array}{l}\text { Neonatal } \\
\text { complication }\end{array}$ & $\begin{array}{l}\text { Women with reduction in } \\
\text { umb. a PI on day } 2 \\
\text { Group A ( } n=53)\end{array}$ & $\begin{array}{l}\text { Women without } \\
\text { reduction in umb. a PI on } \\
\text { day } 2 \text { Group B (n=15) }\end{array}$ & p value \\
\hline Umb. artery PH at birth mean \pm SD (range) & $7.24 \pm 0.19(6.92-7.42)$ & $7.20 \pm 0.16(6.9-7.4)$ & $>0.05(\mathrm{NS})$ \\
\hline Base excess mean \pm SD (range) & $7.13 \pm 4.59(2-22.4)$ & $8.7 \pm 6.2(1.8-23)$ & $>0.05(\mathrm{NS})$ \\
\hline Respiratory distress syndrome (RDS) & $14(26.4 \%)$ & $7(46.7 \%)$ & $>0.05(\mathrm{NS})$ \\
\hline Hypoglycemia & $8(15 \%)$ & $6(40 \%)$ & $>0.05(\mathrm{NS})$ \\
\hline Hypothermia & $6(11.3 \%)$ & $5(33.3 \%)$ & $>0.05(\mathrm{NS})$ \\
\hline Hyperbilirubinemia & $4(7.4 \%)$ & $4(26.6 \%)$ & $>0.05(\mathrm{NS})$ \\
\hline Hypocalcemia & $13(24.5 \%)$ & $4(26.6 \%)$ & $>0.05(\mathrm{NS})$ \\
\hline IVH/NEC & $2(3.8 \%)$ & $1(6.7 \%)$ & $>0.05(\mathrm{NS})$ \\
\hline BPD* & 0 & $1(6.7 \%)$ & $>0.05(\mathrm{NS})$ \\
\hline Sepsis & $7(13.2 \%)$ & $3(20 \%)$ & $>0.05(\mathrm{NS})$ \\
\hline NICU admissions cases (\%) & $25(47 \%)$ & $10(66.7 \%)$ & $>0.05$ \\
\hline Hospital stay in days mean $\pm \mathrm{SD}$ (range) & $11.4 \pm 11.3(1-58)$ & $18.43(2-70)$ & $>0.05$ \\
\hline Neonatal mortality cases (\%) & $3(5.6 \%)$ & $2(13.3 \%)$ & $>0.05$ \\
\hline Perinatal mortality cases (\%) & $6(10.7 \%)$ & $8(38.1 \%)$ & $<0.05$ \\
\hline
\end{tabular}

BPD: brocho-pulmonary dysplasia, NS: not significant, IVH: intraventricular haemorrhage, NEC: necrotising enterocolitis

\section{DISCUSSION}

Doppler plays an important role in management of pregnancies complicated. Till date only few studies are available about the effect of betamethasone on fetoplacental circulation in preterm pregnancies and variable responses on fetoplacental circulation has been noted ${ }^{8-14}$ Hence authors carried out this study to evaluate the effect of betamethasone on fetoplacental circulation in preterm pregnancies complicated with IUGR and effect of these fetoplacental circulation changes on perinatal outcome, if any.

This specific population was chosen because of the high rates of preterm deliveries in pregnancies with IUGR and few studies investigating the effects of corticosteroid administration on fetoplacental Doppler flow in such population. Umbilical artery doppler pulsatility index were being evaluated in this study.

Mean age of women included in this study was $25.36 \pm 3.46$ years. In this present study, authors had women with gestational age ranging from 27.4 weeks to 34 weeks, with a mean gestational age of $31.58 \pm 1.68$ weeks. While in the studies done by Edward et al, Robertson et al, Smolin A et al, mean gestational age on admission was 28.5 weeks, 27.8 weeks and 30.8 weeks respectively. ${ }^{15,16}$

While analyzing this study results authors observed that fetuses with intrauterine growth restriction showed divergent response in terms of changes in umbilical artery Doppler indices following antenatal betamethasone administration (Table 2). Significant reduction in the mean pulsatility index of umbilical artery suggesting improvement in blood flow of umbilical artery were found between 24-48 hours (day 2) after $1^{\text {st }}$ dose of maternal betamethasone administration (as shown in Table 2, 3 and 4). Improvement (decrease) in umbilical artery PI was observed in 56 cases $(73 \%)$ out of total 77 cases whereas, a subgroup of cases (21 cases) did not show any improvement (decrease) in umbilical artery PI on day 2 following betamethasone administration. In this present study, Umbilical artery pulsatility index (PI) 
Mean \pm SD value day 0 (before) and day 2, day 4 (after betamethasone) were $1.73 \pm 0.73$ and $1.54 \pm 0.76$, $1.47 \pm 0.62$ respectively (Table 2,3 and 4 ). Authors found that reduction in umbilical artery pulsatility index were maintained up to day 4 (72-96 hours) after $1^{\text {st }}$ dose of betamethasone with a significant difference in values when compared with their respective day 0 values (Table 4).

Importantly, no placebo or control group was included for obvious ethical reasons, and it is possible that the changes observed relate to other factors, such as bed rest or other medication. However, authors believe that this is most unlikely because it has been previously shown that the umbilical artery Doppler changes were reproduced after a second dose of steroids and in vitro dexamethasone mitigate prostaglandin and $\mathrm{KCl}$-induced vasoconstriction, suggesting that the effect is a direct result of corticosteroid administration. While the women with hypertension were receiving antihypertensive medication, labetalol was used as a primary antihypertensive agent. ${ }^{17,18}$ Few studies have shown vasoconstrictive effect of labetalol on fetoplacental circulation whereas, others researchers have reported no effect of labetalol on fetoplacental resistance. ${ }^{18}$ So, this decrease in mean PI value of umbilical artery cannot be because of the effect of antihypertensive medications like labetalol. Labetalol would be expected to increase rather than decrease the umbilical artery PI. ${ }^{18}$

As in the study by Wallace and Baker, who found a significant decrease in umbilical artery PI along with return of flow in umbilical artery in all the cases with AEDF, authors also noted that $73 \%$ cases (56 cases) with intrauterine growth restriction demonstrated an apparent improvement in umbilical artery Doppler flow parameter, as reduction in umbilical artery PI which persisted up to $4^{\text {th }}$ day of $1^{\text {st }}$ dose of betamethasone (Table 2, 3 and 4). ${ }^{10}$

Results were also comparable with the results of Thuring et al, who observed a significant decrease in umbilical PI on day 2 in 33 IUGR pregnancies and an improvement in umbilical artery flow velocity waveforms following betamethasone in cases who had AEDF or REDF before betamethasone. ${ }^{19}$ In contrast other researchers, like Wijnberger LDE et al, Senat MV et al, Piazze JJ et al, have demonstrated no change in umbilical artery pulsatility index following betamethasone administration in cases of IUGR. ${ }^{20,21}$ Cohlen et al, and Deren O et al failed to observe any change in umbilical artery PI in normal preterm fetuses following betamethasone administration. ${ }^{9,22}$ There was no significant correlation found between the gestational age and Doppler changes in the umbilical artery following betamethasone administration. These results were similar to Thuring et al. ${ }^{19}$

The underlying mechanism of the alterations in the fetoplacental circulation following antenatal betamethasone administration still remains unclear. One of the possible theories to explain changes in fetoplacental circulation accompanied by reduced placental resistance is said to be because of increased secretion of placental corticotrophin releasing hormone after exogenous administration of corticosteroids, which consecutively causes nitric oxide mediated vasodilatation..$^{23-25}$ Another possibility is related to increase in fetal blood pressure which might explain improved fetoplacental perfusion. Experimental studies have shown that administration of betamethasone to fetal sheep leads to an increase in fetal blood pressure. ${ }^{26}$ Furthermore, antenatal corticosteroids treatment of pregnant women has been found to increase blood pressure levels in preterm newborn during the first days of life..$^{27,28}$ In a recent in vitro study on human placentas, Clifton et al, concluded that the mechanism behind the dexamethasone induced vasodilatation might be an endothelium independent mechanism as they did not find any involvement of endothelium derived products like prostaglandin $\mathrm{I} 2$ and nitric oxide. ${ }^{29}$

Accepting that the observed Doppler changes in fetoplacental circulation are betamethasone induced, authors believe that this observation are important for several reasons. First it offers a new model to explore the regulation of the fetoplacental vasculature. Secondly these findings are also important for fetal surveillance undertaken following corticosteroid administration to pregnant women with IUGR. Apart from this, authors also have made an effort to analyze, whether this betamethasone induced changes are beneficial or detrimental for their fetuses.

Hence, authors correlated the findings of umbilical artery changes following betamethasone administration with the perinatal outcome to note whether these changes in fetoplacental circulation following corticosteroids administration are beneficial or detrimental to the IUGR fetus (Table 6, 7, 8, 9).

On analysis of this study data, authors observed that perinatal outcome of 56 women who had displayed decrease in umbilical artery PI after betamethasone (Group A) was better than the perinatal outcome of 21 women (Group B) who did not show decrease in umbilical artery pulsatility index following betamethasone administration. This subgroup was less likely to require ventilator support $(39.6 \%$ in group A versus $86.7 \%$ in Group $A, p$ value $<0.05$ ) than those neonates who had not experienced any improvement in umbilical artery PI and blood flow pattern (Table 7). This study results were similar to results obtained by Robertson et al $(73.5 \%$ versus $93.1 \%) .{ }^{16}$

Neonates who had shown a decrease in umbilical artery PI did better immediately after birth and had better Apgar scores at 1 and $5 \mathrm{~min}$ as compared to neonates who had not displayed any decrease in PI, though this difference was not found to be statistically significant (Table 8). 
This study results were comparable with results of study conducted by Robertson et al. ${ }^{16}$

Intrauterine deaths (Table 6) were found to be significantly higher in women (Group B) who had not shown any decrease in umbilical artery PI as compared to women (Group A) who had shown decrease in umbilical artery PI. (IUD: $28.6 \%$ in Group B versus $5.6 \%$ in Group A, p value $<0.05$ ) Perinatal mortality (Table 9) was also significantly higher in Group B as compared to group A (38.1\% in Group B versus $10.7 \%$ in Group A, p value $<0.05)$. Simchen et al, and Robertson et al, also observed higher mortality rates in their studies. ${ }^{16,30}$

Neonates of women (Group B), who had not shown decrease in umbilical artery PI following betamethasone, required more admissions (66.6\% versus $47 \%)$ in neonatal intensive care unit (NICU), had a longer mean hospital stay (18.4 days versus 11.4 days), higher complications like respiratory distress syndrome, chronic lung disease (bronchopulmonary dysplasia), intraventricular hemorrhage, necrotizing enterocolitis, or hyperbilirubinemia in their neonatal period as compared to neonates (Group A) who had shown an improvement in umbilical artery PI after betamethasone but the differences were not statistically significant (Table 9). It is possible that the numbers of neonates studied were too small to detect any statistically significant difference in these outcomes. Results are similar to results obtained by Robertson et al. ${ }^{16}$ There were no significant differences in either gestational age at birth or birth weight that might explain any outcome differences between the groups (Table 5).

The mechanism behind poor perinatal outcome in women of Group B, who had not shown any decrease in umbilical artery PI, has not been elucidated but potentially could result from a loss of ability of fetus to mount a vascular response to corticosteroids.

Simchen et al, reported that fetuses with IUGR with umbilical artery absent end-diastolic flow that do not show a transient return in end-diastolic flow have a particularly high rate of adverse outcomes. This does not necessarily indicate harm but rather likely indicates that these are fetuses with significant fetoplacental pathophysiology that have lost the ability to mount a vascular response to corticosteroids. As such, they may be at particularly high risk for serious morbidity and actual demise. Robertson et al, also reported results comparable to present study.

However, by using a prospective study design, authors have been able to define a subgroup of IUGR fetuses that demonstrated very different responses (did not show reduction in umbilical artery PI) between 24-48 hours after $1^{\text {st }}$ dose of betamethasone administration, placing them at increased suspicion of neonatal complications and perinatal death. These fetuses may have more extensive placental damage and therefore be a sicker subgroup to begin with, who will require more intensive fetal monitoring, although they could not be defined as such within the IUGR group by their ultrasound/Doppler findings at presentation (day 0 Doppler).

One possible protocol for such monitoring is to perform 'steroid stress test', a Doppler study before and one day after steroid administration in fetuses with IUGR. If decrease in umbilical artery PI or return of end diastolic flow in cases with absent end diastolic flow /reversed end diastolic flow is demonstrated, these fetuses are not likely to deteriorate acutely. However, if no positive response is demonstrated following betamethasone administration (steroid stress test), the fetal venous circulation should be evaluated by Doppler and if abnormal, serious consideration for more intensive fetal monitoring and timely delivery should be given. Another important thing to notify is, all patients with severe IUGR with should get a Doppler examination done prior to betamethasone administration because betamethasone administration causes transient return of umbilical artery blood flow, which can be misleading for the obstetrician if first Doppler examination is done after betamethasone administration.

It is likely that further elucidation of the clinical relevance, if any, of the Doppler responses to antenatal glucocorticoids in the fetus with intrauterine growth restriction will require a meta-analysis of several independent series. To date, this current series and few other studies have been reported. Accordingly, authors would commend other high-risk units to consider prospectively recording the responses to steroids and subsequent perinatal outcomes in this cohort of pregnancies.

The Doppler response to antenatal steroids would be clinically useful information, identifying fetuses at particularly high risk. However, to be used in this manner, clinicians would need to perform daily Doppler studies at the time of steroid administration, a practice that is not currently common place. In absence of such data, this study results, combined with those of Robertson et al and Simchen et al, strongly suggest that clinicians be particularly wary of the fetus with IUGR that fails to show an improvement in Doppler flow parameters in response to antenatal corticosteroids administration.

\section{CONCLUSION}

Authors conducted this observational study to evaluate the effect of maternal betamethasone administration on fetoplacental circulation and effect of fetoplacental circulation changes on perinatal outcome in preterm pregnancy complicated with intrauterine growth restriction, if any. A significant reduction in mean umbilical artery pulsatility index was observed on day 2 following betamethasone administration $(\mathrm{p}<0.001)$, which was maintained till $4^{\text {th }}$ day after $1^{\text {st }}$ dose of betamethasone $(\mathrm{p}<0.05)$. 
On comparison of perinatal outcome, authors found that women (Group A) who showed an improvement (decrease) in umbilical artery pulsatility index following betamethasone administration had a better perinatal outcome as compared to women (Group B) who did not show any improvement (decrease) in umbilical artery pulsatility index following betamethasone administration.

\section{Funding: No funding sources}

Conflict of interest: None declared

Ethical approval: The study was approved by the Institutional Ethics Committee

\section{REFERENCES}

1. Cunningham FG, Leveno KJ, Bloom SL, Hauth JC, Rouse DJ, Spong CY, et al. William's Obstetrics $23^{\text {rd }}$ edition. New York: McGraw-Hill; 2010:842-846.

2. Robert D, Dalziel S. Antenatal glucocoticoids for accelerated fetal lung maturation for women at risk for preterm birth. Cochrane Data Base Syst Rev. 2006;3.

3. Miracle X, Di Renzo GC, Stark A, Fanaroff A, Carbonell-Estrany X, Saling E. Coordinators of WAPM Prematurity working group. Guideline for the use of antenatal corticosteroids for fetal maturation. J Perinat Med. 2008;36:191-6.

4. Crowley P, Chalmers I, Keirse MJNC. The effects of corticosteroids administration before preterm delivery: an overview of the evidence from controlled trials. Br J Obstet Gynaecol. 1990;97:11.

5. Carlan, SJ, Parsons, M, O'Brien, WF, Krammer, J. Pharmacologic pulmonary maturation in preterm premature rupture of membranes. Am J Obstet Gynecol. 1991;164:371.

6. Crowley P. Prophylactic corticosteroids for preterm birth. Cochrane Database Syst Rev. 2000;CD000065.

7. Mulder EJH, Derks JB, Zonneveld MF, Bruinse HW, Visser GH. Transient reduction in foetal activity and heart rate variation after maternal betamethasone administration. Early Hum Dev. 1994;36:49-60.

8. Rotenmensch S, Liberati M, Celentano C, Efrat Z, Bar-Hava I. The effect of betamethasone on fetal biophysical activities and Doppler velocimetry of umbilical and middle cerebral arteries. Acta Obstet Gynaecol Scand. 1999;78(9):768-73.

9. Cohlen BJ, Stigter RH, Derks JB, Mudler EJH, Visser GHA. Absence of significant hemodynamic changes in the fetus after maternal betamethasone administration. Ultrasound Obstet Gynaecol 1996:8:252-5.

10. Wallace EM, Baker LS. Effects of antenatal betamethasone administration on placental vascular resistance. Lancet. 1999;353:1404-7.

11. Piazze JJ, Anceschi MM, La Torre R, Amici F, Maranghi L, Cosmi EV. Effect of betamethasone therapy on maternal - fetal doppler velocimetery. Early Hum Dev. 2001;60:225-32.

12. Edward A, Baker S, Wallace $M$. Changes in umbilical artery flow velocity following maternal administration of betamethasone. Placenta. 2003;24(1):12-6.

13. Raio CL, Surbek D, Tomera S, Siesto G, Lischetti B, Ghezzi F. Haemodynamic effects of betamethasone on growth-restricted fetuses with absent or reversed end diastolic flow. Ultrasound Obstet Gynaecol. 2007;30:367-455.

14. Nozaki AM, Rossana PV, Francisco, Eduardo SVB, Zugaib FM. Fetal hemodynamic changes following maternal betamethasone administration in pregnancy with fetal growth restriction and absent end diastolic flow in umbilical artery. Acta Obstetricia et Gynaecol. 2009;88:350-4.

15. Smolin A, Mazor M, Maymon E, Bashiri A, Dukler D, Bolotin A, et al. Short-term effect of betamethasone administration on MCA blood flow velocimetry on pre term intra uterine growth restricted fetuses. Ultrasound Obstet Gynaecol. 2005;26:309-75.

16. Robertson, Marcus, Murlia, Tong. Predicting perinatal outcome through changes in umbilical artery Doppler study after antenatal corticosteroids in growth restricted fetus. Obstet Gynaecol. 2009;13(3):636-40.

17. Harper A, Murnaghan GA. Maternal and fetal hemodynamics in hypertensive pregnancies during maternal treatment with intravenous hydralazine or labetalol. Br J Obstet Gynaecol. 1991;98:453-9.

18. Clifton VL, Wallace EM, Smith R. Short term effects of glucocorticoids in the human fetal placental circulation in vitro. J Clin Endocrinol Metabol. 2002;87:2838-42.

19. Thuring A, Malcus P, Marsal K. Effect of maternal betamethasone on fetal and uteroplacental blood flow velocity waveforms. Ultrasound Obstet Gynaecol. 2011;37(6):668-72.

20. Piazze J, Anceschi MM, Cerekja A, Cosmi E, Meloni P, Alberini A, et al. The combined effect of betamethasone and ritodrine on the middle cerebral artery in low risk third trimester pregnancies. J Perinatal Med. 2007;35(2):135-40.

21. Senat MV, Ville Y. Effects of steroids on antenatal Doppler in intrauterine growth retarted foetuses. Fetal Diagn Ther. 2000;15:36-40.

22. Deren Ö, Karaer C, Önderoğlu L, Yigit N, Durukan $\mathrm{T}$, Bahado-Singh RO. The effect of steroids on the biophysical profile and Doppler indices of umbilical and middle cerebral arteries in healthy preterm fetuses. Eur J Obstet Gynaecol Reprod Biol. 2001;99(1):72-6.

23. Korebrits $\mathrm{C}, \mathrm{Yu} \mathrm{DH}$, Ramirez MM, Marinoni E, Bocking AD, Challis JR. Antenatal glucocorticoids administration increases corticotrophin releasing hormone in maternal plasma. Br J Obstet Gynaecol. 1998;105:556-61.

24. Marinoni E, Korebrits C, Di Iorio, Cosmi EV, Challis JR. Effect of betamethasone in vivo on placental corticotropin releasing hormone in human pregnancy. Am J Obstet Gynaecol. 1998;178:770-8. 
25. Clifton VL, Read MA, Leitch IM, Giles WB, Boura ALA, Robinson PJ, et al. Corticotropin-releasing hormone-induced vasodilatation in the human fetoplacental circulation: involvement of nitric oxide - cyclic guanosine 3', 5' - monophosphate mediated pathway. J Clin Endocrinol Metab. 1995;80:2888-93.

26. Derks JB, Giussani DA, Jenkins SL, Wentworth RA, Visser GHA, Padbury JF, Nathanielsz PW. A comparative study of cardiovascular, endocrine and behavioural effects of betamethasone and dexamethasone administration to fetal sheep. J Physiol. 1997;499:217-26.

27. Kari MA, Hallman M, Eronen M, Hallman M, Teramo K, Koivisto M, et al. Prenatal dexamethasone treatment in conjuction with rescue therapy of human surfactant: a randomised placebocontrolled multicenter study. Pediatr. 1994;93:730-6.

28. Schwab M, Coksaygan T, Nathanielsz PW. Betamethasone effect on ovine uterine and umbilical placental perfusion at the dose used to enhance fetal lung maturation. Am J Obstet Gynaecol. 2006;194:572-9.

29. Clifton VL, Wallace EM, Smith R. Short term effect of glucocorticoids in human fetal placental circulation in vitro. J Clin Endocrinol Metab. 2007;87:2838-42.

30. Simchen MJ, Alkazaleh F, Adomson SL, Windrim $\mathrm{R}$, Telford J, Beyene J, et al. The fetal cardiovascular response to antinatal steroids in severe early onset intra uterine growth restriction. Am J Obstet Gynaecol. 2004;190:296-304.

Cite this article as: Choudhary N, Kesri A, Nain S, Chaudhary V, Trivedi SS. Effects of antenatal corticosteroids administration on fetoplacental circulation in preterm pregnancies with intrauterine growth restriction and its correlation with perinatal outcome. Int J Reprod Contracept Obstet Gynecol 2020;9:2566-75. 